\title{
Ampliando vozes sobre violência obstétrica: recomendações de advocacy para enfermeira(0) obstetra
}

\author{
Amplifying voices on obstetric violence: recommendations for advocacy by an obstetric nurse \\ Expandiendo las voces sobre la violencia obstétrica: recomendaciones para la advocacy por
enfermera(o) obstetra
}

\author{
Margareth Santos Zanchetta ${ }^{1}$ \\ Walterlânia Silva Santos ${ }^{2}$ (1) \\ Kleyde Ventura de Souza ${ }^{3}$ [D \\ Vanessa Rodrigues Pina ${ }^{1}$ (D) \\ Hilary Hwu ${ }^{1}$ (1) \\ Hannah Stahl ${ }^{1}$ (D) \\ Hannah Argumedo-Stenner ${ }^{4}$ (C) \\ Juliet Osei-Boateng ${ }^{1}$ (]) \\ Rebecca Zimmerman ${ }^{1}$ (1) \\ Érica Dumont Pena ${ }^{3}$ [C] \\ Ivone Evangelista Cabral ${ }^{5}$ (1) \\ Ana Luiza de Oliveira Carvalho ${ }^{5}$ (1) \\ Audrey Vidal Pereira ${ }^{6}$ (1) \\ Bianca Dargam Gomes Vieira ${ }^{6}$ (i) \\ Valdecyr Herdy Alves ${ }^{6}$ (1) \\ Ingryd Cunha Ventura Felipe ${ }^{7}$ (D) \\ Sepali Guruge ${ }^{1}$ (1) \\ Oona St. Amant ${ }^{1}$ (D) \\ Edwaldo Costa ${ }^{1,8}$ (1)
}

Haydée Padilla Vda de Escobar ${ }^{9}$ (b)

1. Ryerson University, Faculty of Community Services, Daphne Cockwell School of Nursing. Toronto, Ontario, Canada.

2. Universidade de Brasília, Faculdade de Ceilândia. Brasília, DF, Brasil.

3. Universidade Federal de Minas Gerais, Escola de Enfermagem. Belo Horizonte, MG, Brasil.

4. Ryerson University, Faculty of Community Services, School of Social Work. Toronto, Ontario, Canada.

5. Universidade Federal do Rio de Janeiro, Escola de Enfermagem Anna Nery. Rio de Janeiro, RJ, Brasil.

6. Universidade Federal Fluminense, Escola de Enfermagem Aurora de Afonso Costa. Niterói, RJ, Brasil.

7. Pesquisador autônomo. Toronto, Ontario, Canadá.

8. Marinha do Brasil. Brasília, DF, Brasil.

9. Organização Pan-Americana da Saúde. Brasília, DF, Brasil.

Autor correspondente:

Margareth Santos Zanchetta

mzanchet@ryerson.ca

Recebido em 10/24/2020

Aprovado em 06/29/2021.

DOl:https://doi.org/10.1590/2177-9465-EAN-2020-0449

\section{Resumo}

Objetivos: explorar as demandas das mulheres, bem como do público em geral, para melhorar a qualidade da assistência obstétrica; discutir as mudanças potenciais sugeridas pelos respondentes para tal prática assistencial. Método: pesquisa multicêntrica realizada por meio da plataforma Opinio, explorando opiniões dos participantes de três cidades da região Sudeste do Brasil. Tratamento dos dados por estatística descritiva e análise temática. Resultados: respondentes $(n=414)$ na faixa etária 33-37 anos (26\%), incluindo mulheres (75\%) com mais de 15 anos de escolaridade, casadas (45\%) e com um filho (35\%), revelaram lacuna de conhecimentos sobre a violência obstétrica e os direitos da mulher. Jornal, rádio e televisão são as principais fontes de informação. O enfrentamento da violência obstétrica dar-se-ia por apoio familiar. Para a práxis renovada sugeriu-se a educação coletiva sobre direitos aos cuidados obstétricos $(53,1 \%)$ e o atendimento humanizado $(38,2 \%)$ mobilizando o poder profissional para consolidar a humanização. Temas analíticos centrais incluíram situação vivenciada pelas mulheres e contexto idealizado de prática. Conclusão e Implicações para a prática: o debate incrementa a humanização e a governança compartilhada. Recomendações propostas para advocacy coadunam com a perspectiva global da promoção de saúde das mulheres e liderança social.

Palavras-chave: Advocacia em Saúde; Competência Profissional; Educação em Enfermagem; Prática Profissional; Violência contra a Mulher

\section{Abstract}

Objectives: Explore women's and the general public's demands to improve the quality of obstetric care. Discuss respondents' suggestions to improve obstetric care, and propose recommendations for nursing advocacy in matters of obstetric violence. Method: A multi-site online survey (in three cities in Brazil's southeastern region) hosted by Opinio platform exploring the respondents' opinions. Data was analyzed by descriptive statistics and thematic analysis. Results: Respondents $(n=414)$ aged $33-37$ years (26\%), including women (75\%) with more than 15 years of schooling, who are married $(45 \%)$ and with one child $(35 \%)$, demonstrated a knowledge gap on obstetric violence and women's rights. Newspapers, radio, and television were cited as the main sources of information. Family support was a suggested strategy to deal with obstetric violence. For the renewed praxis, collective education on obstetric care rights $(53.1 \%)$ and humanized care $(38.2 \%)$ were suggested to mobilize professional power to consolidate humanization in care. Central analytical themes included situations faced by women and an idealized context of practice. Conclusion and implications for practice: Discussion in organizations increases humanization and shared governance. Recommendations proposed for advocacy are consistent with the global perspective of women's health promotion and social leadership.

Keywords: Education, nursing; Health advocacy; Professional competence; Professional practice; Violence against women.

\section{REsumen}

Objetivos: explorar las demandas de las mujeres, así como del público en general, para mejorar la calidad de la atención obstétrica Discutir los posibles cambios sugeridos por los encuestados para esta práctica de cuidado y, Proponer recomendaciones para la promoción por la enfermera en cuestiones de violencia obstétrica. Método: investigación multicéntrica realizada a través de la plataforma Opinio, explorando las opiniones de los participantes de tres ciudades en el sureste de Brasil. Tratamiento de datos mediante estadísticas descriptivas y análisis temáticos. Resultados: demandados ( $n-414)$ de 33 a 37 años (26\%) incluyendo mujeres (75\%) con más de 15 años de escolarización, casado (45\%) y con un niño (35\%) reveló una brecha de conocimiento sobre la violencia obstétrica y los derechos de las mujeres. El periódico, la radio y la televisión son las principales fuentes de información. La confrontación se basaría en el apoyo de la familia. Para la renovada praxis, se sugirió la educación colectiva sobre los derechos de atención obstétrica $(53,1 \%)$ y la atención humanizada $(38,2 \%)$ movilizar el poder profesional para consolidar la humanización. Los temas analíticos centrales incluyeron una situación experimentada por las mujeres y un contexto idealizado de práctica. Conclusión e implicaciones para la práctica: el debate aumenta la humanización y la gobernanza compartida. Las recomendaciones propuestas para la promoción son coherentes con la perspectiva mundial de la promoción de la salud y el liderazgo social de las mujeres.

Palabras clave: Competencia Profesional; Defesa de la Salud; Educación en Enfermería; Práctica Profesional; Violencia contra la Mujer. 
Zanchetta MS, Santos WS, Souza KV, Pina VR, Hwu H, Stahl H, Argumedo-Stenner H, Osei-Boateng J, Zimmerman R, Pena ÉD, Cabral IE, Carvalho ALO, Pereira AV, Vieira BDG, Alves VH, Felipe ICV, Guruge S, Amant OS, Costa E, Escobar HPV

\section{INTRODUÇÃO}

A enfermagem mundial protagoniza um momento político ímpar em torno da profissão, organizado por meio de movimentos globais como o NurseManifest ${ }^{1}$ e o Nursing Now ${ }^{2}$, que conclamam a(o)s enfermeira(o)s para maior ativismo político, seguindo desafio lançado por enfermeiras canadenses para ações de advocacy ${ }^{\text {* }}$ em prol da saúde (advocacia em saúde) das populações e não mais de um paciente ${ }^{3}$. A repercussão desses movimentos no Brasil reflete-se por meio da Carta de Brasília², que destaca, entre suas metas principais, o desenvolvimento da liderança e a disseminação de práticas baseadas em evidências científicas da Enfermagem. Tais metas relacionam-se com a voz ativa e a presença de enfermeira(o)s em espaços sociais receptivos à inovação da prática, a competência profissional para a tomada de decisão e de formulação de políticas e confirmam a relevância social desta pesquisa no atual momento político também para a Enfermagem brasileira.

A literatura internacional sobre educação política de enfermeira(o) s no Canadá e nos Estados Unidos (no pioneirismo em advocacy em saúde das mulheres socialmente marginalizadas ${ }^{4}$ ) indica que a educação formal é espaço único em que a identidade política da(o)s estudantes de Enfermagem se define ${ }^{5-6}$. A incorporação de tal conteúdo curricular permanece inconsistente, já que cerca de $91 \%$ da(o)s estudantes de Enfermagem americanos não se engajam em ativismo político, provavelmente espelhando o engajamento político de seus professores ${ }^{5}$. Alguns professora(e)s buscam incutir um sentido de responsabilidade política na nova geração de enfermeiras(os) ${ }^{7}$. Destacamos que não identificamos evidências sobre conteúdo curricular para a educação em Enfermagem especificamente sobre o ensino de advocacy no Brasil.

Para a prática da advocacy política, exige-se julgamento clínico para produzir mudança em nível individual acrescido de habilidades políticas para colaborar com apoiadores internos ou externos no setor de cuidados de saúde em níveis micro, meso e macro-organizacional ${ }^{4}$. Na formação acadêmica, as oportunidades para identificar áreas de maior demanda e, portanto, de construir tal identidade política são inúmeras. Entre elas, encontra-se a proteção dos direitos humanos das mulheres como foco em definição de políticas internacionais de ajuda e de cooperação tecnocientífica.

A internacionalização da educação e da pesquisa oferece outras possibilidades. A sólida parceria científica Brasil-Canadá ${ }^{8}$ e a Canada's Feminist International Assistance Policy ${ }^{9}$ para atividades globais, que protejam direitos humanos, inclusão social e equidade, serviram de marco para uma pesquisa internacional fortalecendo a pesquisa em Enfermagem ${ }^{10}$ prosseguindo atividades da Ryerson Research Chair in Urban Health na área de violência contra a mulher. A pesquisa explorou temas presentes nas experiências coletivas no Brasil quanto à implementação do Programa de Humanização no Pré-Parto e Nascimento (PHPN) ${ }^{11}$. Neste artigo relatamos seus resultados e recomendamos ações de advocacy a enfermeira(o)s como tradução de conhecimentos empíricos para a prática ${ }^{12}$ com intuito de proteger os direitos das mulheres ${ }^{\mathrm{b} *}$ e coibir situações de violência obstétrica, ${ }^{13}$ expandindo, assim, seus papéis na divulgação de conhecimentos ${ }^{14}$.

\section{REVISÃO DE LITERATURA}

Violência obstétrica engloba ameaça aos direitos à vida, à saúde e à integridade física ${ }^{15-16}$. Inclui procedimentos técnicos coercivos ou não consentidos, recusa em administrar analgésico e negligência durante o parto, assim como falta de confidencialidade, violações de privacidade, recusa de internação nas instituições de saúde e retenção de mulheres e seus recém-nascidos nas instituições, após o parto, por incapacidade de pagamento ${ }^{15-16}$. Identificada em diferentes paíse ${ }^{17-19}$, coibir esta forma de violência constitui uma questão de governança nos sistemas de saúde. É condição obrigatória para que sejam respeitados e protegidos os direitos humanos das mulheres e o cumprimento de promessas de implantação de políticas públicas baseadas em direitos civis $^{20}$, inclusive em situações de crises humanitárias ${ }^{21}$ vividas por mulheres grávidas em busca de asilo político.

Pesquisas brasileiras documentaram tal violência ${ }^{22}$ por meio de procedimentos não explicados e não autorizados $(27,3 \%)^{23}$, recusa de permissão para acompanhantes $(9,3 \%)^{24-25}$, e elevada taxa de cesarianas e nascimentos prematuros ${ }^{26}$, registrando o impacto na saúde de indivíduos, famílias, comunidades e sociedades ${ }^{25}$. O ativismo político latino-americano, com destaque ao movimento brasileiro de humanização do parto, ainda é insuficiente para coibir tal violência ${ }^{27}$. Pelas dificuldades no acesso e na assistência, tal julgamento negligencia as mulheres socialmente vulneráveis, devido ao risco reprodutivo maior entre as mulheres afrodescendentes ${ }^{28-29}$. Essas dificuldades são explicadas pela invisibilidade e resistência ao reconhecimento do racismo obstétrico, que se refletem nos serviços de saúde prestados $^{30-31}$.

A violência obstétrica enquadra-se também no elenco de violação dos direitos humanos das mulheres, sendo subnotificada, ou pior, não notificada, devido a constrangimentos, humilhações ou medo de que os agressores queiram vingança ${ }^{32}$. No Brasil, a implantação da Rede Cegonha avançou na instalação de centros de apoio ao desenvolvimento de boas práticas na gestão e assistência humanizada obstétrica e neonatal ${ }^{33-35}$ e, ainda, promove espaços de apoio à saúde materna e infantil, incorporando experiências e novas tecnologias obstétricas ${ }^{36}$. A humanização em uma rede articulada estendeu-se à estrutura familiar pelo HumanizaSUS ${ }^{37}$, (Sistema Único de Saúde (SUS)) guiando ações políticas para garantir a melhoria do acesso, da cobertura, qualidade e humanização da atenção obstétrica e neonatal, integrando ações do pré-natal e acompanhamento da criança na rede de atenção básica e nas maternidades. Diretrizes específicas ${ }^{38}$ guiam, ainda, o enfrentamento da violência contra a criança desde a concepção, por meio da humanização no acolhimento, escuta ativa e sensível do casal durante o pré-natal, acompanhamento do processo gestacional e crescimento e desenvolvimento do bebê. A implementação efetiva dos programas de humanização ${ }^{34,39}$ no SUS reforçou a defesa dos direitos ao cuidado humanizado por enfermeira(o)s 
assistenciais, docentes e pesquisadores. Em todas as áreas de atuação, enfermeira(o)s podem assumir o papel de educadores(as) sobre direitos civis, com vistas a melhorar a qualidade de vida, incluindo a educação para a saúde.

Cumpre destacar que não identificamos evidências internacionais sobre consciência da população acerca de um programa nacional similar, considerando o pioneirismo do PHNP, que impossibilita comparações. Assim, o ineditismo desta pesquisa concentrou-se em ouvir percepções da sociedade brasileira sobre a existência do PHPN e apontar áreas de mudanças para que sua implementação ocorresse em estreita aliança entre clientela e profissionais de saúde, para subsidiar mudanças na prática assistencial interdisciplinar e na gestão de serviços de saúde.

A pesquisa explorou temas presentes nas experiências coletivas no Brasil quanto à implementação do Programa de Humanização no Pré-Parto e Nascimento (PHPN) ${ }^{11}$. As bases conceituais do PHPN ${ }^{11}$ constituíram o marco conceitual que guiou esta pesquisa. Buscando evidências para subsidiar mudanças para elevar a qualidade da assistência, esta pesquisa respondeu às seguintes perguntas norteadoras: (a) Quais são as solicitações apresentadas pelas mulheres e pelo público em geral ${ }^{* *}$ para melhorar a qualidade dos serviços prestados por profissionais de saúde, assim como pelos recursos comunitários existentes para apoiar as mulheres que lidam com problemas de violência obstétrica? (b) O que as mulheres e o público em geral recomendam aos profissionais de saúde para modificar as práticas de violência obstétrica?

A pesquisa objetivou: (a) explorar as demandas das mulheres, bem como do público em geral, para melhorar a qualidade da assistência obstétrica; e (b) discutir as mudanças potenciais sugeridas pelos respondentes para tal prática assistencial.

\section{MÉTODO}

Pesquisa exploratória inspirada na abordagem da etnografia crítica que reflete sobre o exame crítico das questões de cultura, saberes e ações. Esse tipo de etnografia aprofunda e refina os compromissos éticos para desenvolvermos e agirmos baseados em compromissos de valores, no contexto de agendas políticas, inclusive as da dinâmica de poder entre indivíduos ${ }^{40}$. A pesquisa foi realizada por meio de uma plataforma online ${ }^{41}$ para ampliar o alcance a possíveis participantes e foi implantada em três cidades do Sudeste brasileiro, entre julho/2019 e fevereiro/2020. Considerando a complexidade e amplitude da pesquisa, neste artigo apresentamos um recorte dos dados conforme demandas para a melhoria da qualidade dos serviços de saúde assim como identificação de recursos comunitários relacionados ao suporte a mulheres vítimas de violência obstétrica e recomendações aos profissionais de saúde por mulheres e homens, representando a sociedade civil.

Participaram da investigação mulheres e público em geral, recrutados por meio da publicação de anúncios contendo o link para a plataforma Opinio, afixados em instituições de saúde, em páginas do Facebook e Twitter que solicitavam a ampla divulgação nas redes sociais. Também foram enviados por e-mail anúncios aos indivíduos das redes profissionais e sociais da equipe de pesquisa. Devido à adesão espontânea dos participantes, em resposta ao convite direto ou indireto recebido também pelos colaboradores no recrutamento, o método de seleção foi o não probabilístico combinado com o método "bola de neve", compatíveis com a pesquisa online ${ }^{41}$. Como critérios de inclusão aplicáveis a este recorte, considerouse: ter pelo menos 18 anos de idade no momento da pesquisa e decidir participar voluntariamente da pesquisa respondendo a um formulário online. O critério de exclusão foi identificar-se como de origem indígena. Os formulários originais de coleta de dados, para serem respondidos por mulheres, e o outro, para o público em geral, foram elaborados pela equipe canadense e revisados pela equipe brasileira quanto às suas propriedades semânticas, observando as características linguísticas regionais e a adequação ao nível de linguagem popular. Em suma, o método de trabalho incluiu a tradução livre Inglês-Português, com adaptações regionais.

Esses formulários exploraram a opinião dos respondentes sobre questões relacionadas à violência obstétrica e à melhora da assistência pré-natal, no trabalho de parto e parto, e apresentavam três perguntas em comum de identificação sociodemográfica (idade, sexo e anos de escolaridade) e duas perguntas adicionais para as mulheres (número de gravidezes, número de filhos e situação conjugal). As demais perguntas com seleção de múltiplas alternativas exploraram: (a) Modo de disponibilização das informações sobre a violência que as mulheres podem enfrentar quando são assistidas em organizações de saúde durante a gestação, o trabalho de parto e no parto; (b) Quem seria(m) $\mathrm{a}(\mathrm{s})$ pessoa(s) com as quais procurariam apoio e ajuda, se uma mulher sofresse qualquer forma de violência moral, emocional ou física durante o trabalho de parto e no parto. Três perguntas abertas exploraram a percepção dos respondentes quanto a: (a) conhecimento das mulheres locais sobre a violência obstétrica e direitos das mulheres para uma assistência obstétrica segura e respeitosa; (b) ações profissionais para uso de seu poder e autoridade para proporcionar melhor qualidade de atendimento às mulheres nos momentos do trabalho de parto e no parto; (c) ações propostas para modificar todas as práticas profissionais que possam levar mulher e parceiro(a)/acompanhante a sofrerem alguma forma de violência contra a mulher no trabalho de parto e no parto.

A coleta de dados ocorreu na aplicação dos formulários online disponibilizados em Português na plataforma Opinio, da universidade canadense. A plataforma gerou um relatório final em que constavam os dados sociodemográficos e resultados quantitativos compilados e analisados pela estatística descritiva ${ }^{42}$. O texto das respostas abertas foi submetido à leitura crítica e, em seguida, submetido a procedimentos recomendados pela técnica de análise temática ${ }^{43}$ : identificação de ideias emergentes, após repetidas leituras da compilação de respostas escritas; reflexão sobre tais ideias organizadas em grupos; tentativa de identificação de categorias e criação de temas possíveis para responder às perguntas de pesquisa. 
Para este recorte, a análise temática dos dados foi precedida por interpretação dos resultados quanti-qualitativos, possibilitando sua integração com as respostas específicas sob a forma de sugestões para modificação da prática profissional. Tais sugestões foram manualmente exploradas nos conteúdos do relatório produzido pela plataforma Opinio focalizando-se na ideia principal apresentada pelos comentários, sugestões, e recomendações. Tal procedimento metodológico foi conduzido para explorar a tendência dos achados qualitativos pela leitura flutuante, seguida de revisão da compreensão dos achados, resultando na identificação de grupos de ideias (e.g. sugestões e comentários). Foram produzidos dois temas analíticos centrais: (i) Situação experienciada pelas mulheres, incluindo os subtemas; Disponibilidade de informações; Nível de (des) conhecimento sobre direitos obstétricos; Ajuda requerida e (ii) Contexto idealizado de práxis com os subtemas; Uso do poder profissional e Mudança prospectiva da práxis, que guiaram a exploração do corpus para a análise ${ }^{43}$.

O protocolo de pesquisa foi revisado e aprovado pelo Comitê de Ética em Pesquisa da universidade canadense, REB nำ2019063, e pela Comissão Nacional de Ética em Pesquisa/BR no 3461.935 (Brasil), cumprindo as exigências éticas estabelecidas para estudos envolvendo seres humanos. O consentimento livre e informado foi obtido com base nos princípios do consentimento implícito. Entendeu-se por consentimento implícito a ação de o participante acessar a plataforma online Opinio e clicar (avançar) no link fornecido nos anúncios indicando que o consentimento fora implícito e concedido pelo participante após a leitura do termo de consentimento, embora não tenha sido expresso verbalmente ou por escrito.

\section{RESULTADOS}

Em cada cidade foram constituídas duas amostras de respondentes para a pesquisa online, seguindo tendência da pesquisa internacional ${ }^{44}$, com as mulheres e o público em geral, perfazendo um total de seis subamostras. Cumpre destacar a atração do interesse de 700 pessoas em acessar os formulários nos referidos centros, das quais $60 \%(n=414)$ consentiram implicitamente e os responderam. Desses 414 participantes, 342 responderam ao formulário específico para mulheres e outro, destinado ao público geral, foi respondido por 56 mulheres e 16 homens. Nos parágrafos seguintes, a estatística descritiva refere-se ao cômputo de frequência e porcentagem dos resultados compilados pelos dois formulários descritos. Quanto à faixa etária, 26\% declararam pertencer à faixa etária entre 33-37 anos. Nas três subamostras somadas femininas dos locais de pesquisa, $75 \%$ delas informaram ter mais de 15 anos de escolaridade, $45 \%$ eram casadas e $35 \%$ têm apenas um filho.

\section{Demandas para melhorar a qualidade da assistência obstétrica}

Para a pergunta: "Onde estão disponíveis as informações sobre a violência que as mulheres podem enfrentar quando são assistidas em organizações de saúde durante a gestação, o trabalho de parto e no parto?", obtivemos 785 respostas entre as 7 alternativas possíveis de escolha, podendo-se assinalar mais de uma resposta. As respostas foram: Apenas ocasionalmente jornal, rádio e televisão locais falam sobre esse problema ( $n=165 ; 21 \%)$; Grupos comunitários que defendem os direitos das mulheres falam sobre esse problema $(n=157$; $20 \%$ ); Apenas o Facebook, Instagram, Twitter têm postado sobre esse problema ( $n=149 ; 19 \%)$; Entre as mulheres, falamos muito sobre esse problema ( $n=147 ; 18.7 \%)$; Ninguém fala sobre esse problema ( $n=77 ; 9.8 \%)$; Uma Organização Não Governamental (ONG) local nos ensinou sobre esse problema ( $n=46 ; 5.8 \%)$ e Profissionais dos centros comunitários de saúde nos ensinam sobre esse problema $(n=44 ; 5.6 \%)$.

Quanto à pergunta "O que as mulheres locais sabem sobre a violência obstétrica e os direitos das mulheres para uma assistência obstétrica segura e respeitosa?", 22\% ( $n=91)$ informaram não saber respondê-la. As mulheres informaram uma lacuna de conhecimento sobre o tema entre a população feminina ( $n=272,65,7 \%)$, assim como o público geral $(n=51$; $12,3 \%)$, como ilustrado a seguir:

Poucas mulheres na comunidade em geral sabem e falam sobre o assunto. Minha mãe sofreu violência obstétrica nos três partos dela e ela nunca soube nomear isso. No primeiro, usaram fórceps, ela teve hemorragia pós-parto e foi muito maltratada no parto. No segundo, ouviu piadinhas sobre o fato de estar com medo do parto normal (devido à experiência do primeiro), no terceiro, teve pré-eclâmpsia e foi maltratada também. (Mulher, Belo Horizonte)

Muitas mulheres aqui nem ao menos reconhecem uma violência obstétrica, acreditando que os procedimentos adotados são seguros, adequados e normais, tais como a episiotomia. (Público, Niterói)

Acho que quase nada... Quando eu tive meus três filhos, todos partos de cesarianas, ninguém tinha me falado nada. Só ouvia mulheres contando que quando foram ter bebês, ouviam as enfermeiras falando: tá sentindo dor, tá? na hora de fazer não doeu, não chamou ninguém... coisas desse nível. (Mulher, Rio de Janeiro)

Para a pergunta "Se uma mulher sofrer qualquer forma de violência moral, emocional ou física durante o trabalho de parto e no parto e quiser apoio, a quem ela, mais provavelmente, pediria ajuda?", entre as alternativas de respostas, estavam: Amigos, Delegacia de Proteção à Mulher, Família, Líder religioso, Profissionais de saúde, Ninguém poderia ajudar e Outros. Houve uma predominância de respostas para a opção Família por mais da metade dos respondentes $(56,3 \%$ ) nas três cidades, seguida por Amigos (13,1\%) e Delegacia de Proteção à Mulher (10,7\%). Ao responderem a opção Outros, como fonte de ajuda, referiamse à igreja, polícia, ONG - percebidas como locais de ofertas de serviços de apoio psicológico e jurídico -, visita domiciliar, grupos de acompanhamento (presencial ou virtual) e escuta individual. Uma respondente alertou sobre a importância e a coragem de denunciar: 
Não sei exatamente, eu procuraria denunciar em redes sociais e procuraria me informar sobre as respectivas redes de proteção. Sofri violência obstétrica em meus dois partos, sem saber que se tratava disso. (Mulher, Belo Horizonte)

Uma outra pergunta, do tipo aberta, concentrou-se em "O que os profissionais devem fazer para usar seu poder e sua autoridade para proporcionar melhor qualidade de atendimento às mulheres nos momentos do trabalho de parto e no parto?". Um total de 404 sugestões foram fornecidas, tendo como temas respeito, empatia, escuta e orientação da mulher, assim como realização de treinamento profissional com foco na humanização da assistência, exemplificado nas falas a seguir:

Empoderar as mulheres sobre os seus direitos e apoiá-las em suas escolhas. (Mulher, Belo Horizonte)

Combater todo o tipo de violência e buscar sensibilizar os profissionais à sua volta para fazer o mesmo. (Público, Belo Horizonte)

Devem, primeiramente, respeitar a mulher e sua família, suas decisões, crenças, costumes e escolhas. Devem desconstruir que profissionais de saúde têm pleno poder e autoridade sobre a saúde daqueles que eles prestam cuidado. Devem ser menos intervencionistas e medicalizantes em situações que não exigem tal abordagem. (Mulher, Niterói)

Tranquilizar e respeitar as parturientes, assegurando-as dos seus direitos. (Público, Niterói)

Orientar sobre os direitos da mulher, sobre a legislação vigente e também como é o processo da assistência, principalmente, quando é a primeira gravidez. Acredito que o conhecimento acerca do processo seja um fator determinante para evitar o abuso de poder de algum profissionale a consequente violência obstétrica. (Mulher, Rio de Janeiro)

Prestar o melhor atendimento, explicar todos os procedimentos e deixar a paciente escolher a melhor opção para o seu tratamento e o orientar de maneira clara. Encaminhar para terapia, cuidar do bem-estar físico e emocional da mulher assistida. (Público, Rio de Janeiro)

\section{Potenciais mudanças na prática assistencial}

Em relação à pergunta aberta, "O que deveria ser feito para modificar as práticas profissionais que levam mulher e parceiro(a)/ acompanhante a experienciar qualquer forma de violência no trabalho de parto e no parto?", os respondentes indicaram 361 propostas de mudanças. A tendência das sugestões, em sua maioria, foi a necessidade de educar as mulheres, os profissionais, os gestores e a sociedade, destacando-se as expressões de um misto de apelo por justiça social e responsabilização ético-profissional:

Através de denúncia/prática de avaliação do próprio local a partir de instrumentais que o próprio Serviço pudesse disponibilizar, canais de atendimento, fichas de avaliação, entrevistas antes da alta, etc. (Mulher, Belo Horizonte)
Discussão ampla na sociedade, formação de profissionais, discussão nas escolas, leis mais duras, intervenção no "lobby" médico. (Público, Belo Horizonte)

Deveria ser modificado, desde os ensinamentos culturais e educacionais. O sistema, hoje, ainda ensina que mulheres são fracas, e essa modificação vem do berço. Vem dos ensinos e das mudanças de padrões. Modificando o modo de nascer, vamos mudando o mundo. (Mulher, Niterói)

Uma mudança em diferentes áreas da vida, não só na médica. Uma mudança nas práticas de trabalho, de formação, de cuidado, não há como agir sobre esse problema com políticas isoladas, devendo ser consideradas as políticas de gênero, de educação, de formação profissional, de informação sobre corpo e sexualidade, etc. (Público, Niterói)

Maior investimento em saúde, melhor conscientização dos papéis de todos os envolvidos, ambiente menos insalubre, fiscalização de auditores, de auditores externos. (Mulher, Rio de Janeiro)

Ampla divulgação sobre o tema. Muitas mulheres sofrem violência e não têm consciência porque onde ela vive sempre aconteceu e ninguém nunca reclamou. Tem que ser feito um trabalho de conscientização para que os profissionais mudem e as pacientes comecem a cobrar e denunciar. (Público, Rio de Janeiro)

O cerne dos resultados encontra-se na exiguidade de informações disponíveis para provocar as reivindicações de direitos das mulheres, o que sugere um processo de educação coletiva para a prevenção de seu aviltamento, com a expansão do letramento político. Os dados quantitativos foram: (a) Informar as mulheres, a família, a sociedade e os profissionais sobre direitos aos cuidados obstétricos ( $n=692 ; 53,1 \%)$; (b) Oferecer atendimento humanizado ( $n=452 ; 38,2 \%)$ e (c) Mudar a cultura do silêncio, favorecendo a denúncia, a fiscalização e a correção da prática profissional $(n=103 ; 8,7 \%)$.

Da análise temática emergiram dois temas centrais: (i) Situação experienciada pelas mulheres, incluindo os subtemas Disponibilidade de informações, Nível de (des)conhecimento sobre direitos obstétricos e Ajuda requerida. Para todos os respondentes, a situação vivenciada pelas mulheres advém da indisponibilidade de informações em seus ambientes sociais que, por sua vez, é o que estabelece o nível de (des) conhecimentos sobre seus direitos protegidos pelo PHPN. Tal percepção de desconhecimento conduziu a solicitações de ações ampliadas de educação sobre tais direitos, sendo esta a maior demanda dos respondentes. Revelou-se que a maioria das mulheres são desprovidas de informações sobre a caracterização da violência obstétrica. À percepção coletiva sobre o inquestionável poder de decisão do profissional de saúde sobre os corpos femininos soma-se a falta de conhecimento para identificar e reconhecer a violência obstétrica. Denunciar e obter apoio jurídico para evitar que práticas e atos indevidos se repitam requer a mobilização de canais de comunicação com ampla penetração social. Divulgare alertar a população feminina e a sociedade sobre o aviltamento 


\section{Advocacy e violência obstétrica}

Zanchetta MS, Santos WS, Souza KV, Pina VR, Hwu H, Stahl H, Argumedo-Stenner H, Osei-Boateng J, Zimmerman R, Pena ÉD, Cabral IE, Carvalho ALO, Pereira AV, Vieira BDG, Alves VH, Felipe ICV, Guruge S, Amant OS, Costa E, Escobar HPV

dos direitos das mulheres envolve atividades sistematizadas, integradas e contínuas de educação em diferentes espaços sociais (e.g., escolas, unidade básica de saúde).

(ii) Contexto idealizado de práxis com os subtemas: Uso do poder profissional e Mudança prospectiva da práxis. As evidências desenharam um contexto idealizado de práxis em que o uso do poder profissional para a mudança prospectiva da práxis seria possível com ações de humanização. A operacionalização se daria por ações educativas em massa para amplo conhecimento da existência do PHPN em um cenário de oportunidades para solidificar a advocacy por enfermeira(o)s, disseminando conhecimentos, corroborando resultados de outras pesquisas em várias áreas subjacentes à da promoção da saúde ${ }^{45}$ sobre respeito aos direitos da mulher e contra a violência de gênero. ${ }^{46-48}$ Ações articuladas em espaços sociais em que a prevenção seja prioritária pela humanização da assistência multidisciplinar associamse a questões estruturais e de recursos disponíveis, além do compartilhamento de responsabilidades entre profissionais e administradores. ${ }^{49} \mathrm{~A}$ prevenção poderia ainda beneficiar-se da ação redesenhada do profissional de relações públicas que, ao invés de zelar por interesses institucionais, promoveria as vozes da clientela socialmente marginalizada para fazer ecoar suas reivindicações na sociedade, resultando em ação efetiva na resolução das questões de violência de gênero nos países de renda média ${ }^{50}$.

A Figura 1 abaixo ilustra a súmula integrativa das evidências que conduzem a análise temática que, por sua vez, sinaliza implicações multidimensionais na práxis.

\section{DISCUSSÃO}

Nesta seção discutem-se somente os resultados e achados centrais que foram analisados (e não aqueles em seu estado bruto) - considerados como foco prioritário para o desenvolvimento dessa seção. As evidências produzidas por esta pesquisa indicam que mulheres, profissionais, famílias e gestores requerem apoio para efetivarem uma mudança cultural da assistência obstétrica. A situação experienciada por mulheres pode ser modificada pela mobilização comunitária; o aumento do controle, pela comunidade, para reduzir iniquidades em saúde pode provocar uma mudança na distribuição do poder ${ }^{51}$. Os resultados indicam a necessidade do empoderamento comunitário, pois este representa a base fundamental para o encorajamento ao suporte mútuo e suporte à construção de capacidades para se ter acesso a serviços e verbalização de preocupações para incrementar o controle pessoal sobre suas vidas $^{52}$. Dessa forma, os resultados indicam a relevância de se assessorarem os grupos existentes para criação de mecanismos de defesa dos direitos das mulheres pautados no monitoramento local/estadual da implementação do PHPN e sobre os casos denunciados de violência obstétrica, assim como promover o amplo debate sobre direitos obstétricos, negligência no cuidado obstétrico ou violações do PHPN. Necessário ainda observar que, a implantação de políticas internacionais reforçando direitos humanos universais, das mulheres e da criança, guiam a melhora da qualidade de vida dos indivíduos e das comunidades ${ }^{53}$.

Corroborando nossos resultados, importante frisar que direitos humanos no nascimento tornaram-se uma discussão global centrada em evidências científicas, compaixão ${ }^{54}$ e no reconhecimento de que as mulheres enquanto cidadãs desempenham um papel poderoso na promoção de saúde e no suporte mútuo ${ }^{55}$. Apesar de haver poucos estudos na área de empoderamento comunitário das mulheres e seus direitos nesta área específica, enfermeira(o)s e outros profissionais defendendo suas clientelas reconhecem iniciativas significativas lideradas por mulheres ${ }^{55-56}$. Portanto, a importância de se promover a saúde das mulheres

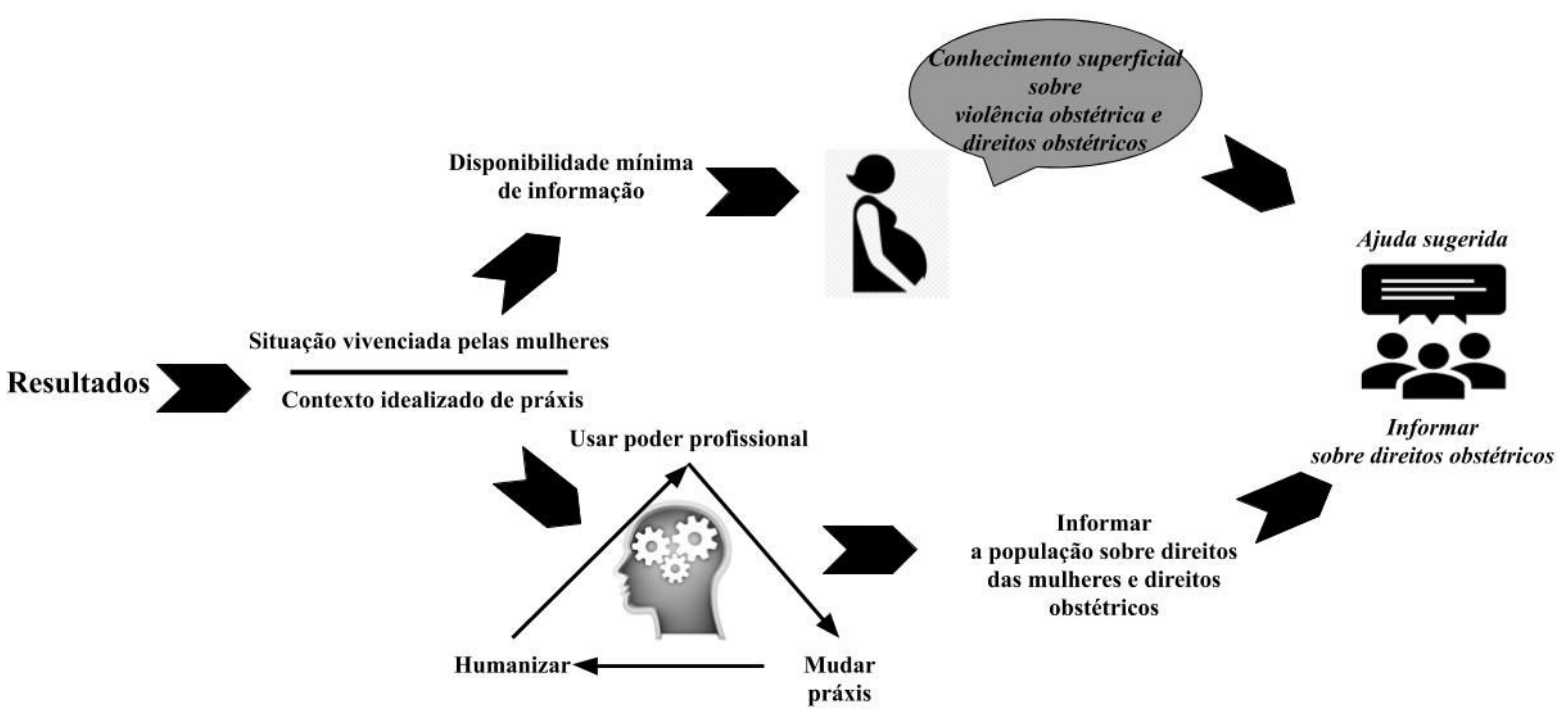

Figura 1 - Síntese da voz ampliada das mulheres e do público inspirando a práxis renovada. Fonte: Elaborada pelos autores. 
e seu envolvimento no movimento de promoção da saúde é certamente por meio de ações inovadoras de advocacy e comunicação $0^{52,56}$. Educar mulheres no ciclo gravídico-puerperal promove empoderamento por meio do aumento da autoestima e da autonomia ${ }^{56}$ para optar pelo parto fisiológico, ${ }^{57}$ a quebra do ciclo do silêncio ${ }^{58}$ e a redução da violência institucional..$^{59}$

Em paralelo, almeja-se uma mudança da práxis para incrementar a assistência humanizada. Neste contexto, cabe enfatizar que a Enfermagem, no contexto de mudanças globais (e.g., mobilidade geográfica, avanços tecnológicos, mudanças políticas e sociais) ${ }^{60-61}$, usa a comunicação social crítica para tal empoderamento. Isso se dá pelo trabalho diferenciado especialmente de enfermeira(o)s possuidora(e)s de habilidades de pensamento crítico enquanto humanizam a assistência ${ }^{55,61}$. Tal ação pode estreitar a distância entre o PHPN, a legislação e a assistência obstétrica ${ }^{59}$, exigindo treinamento específico de profissionais de saúde com sólida base em conteúdos de ética, gênero e direitos humanos para que mudanças sólidas aconteçam ${ }^{23}$.

As(Os) enfermeira(os), ao se educarem em temas políticos, podem promover o empoderamento de suas clientes e suas comunidades, já que igualdade de gênero e empoderamento das mulheres encontram-se entre os Objetivos de Desenvolvimento Sustentável ${ }^{62}$. Embora aparentemente levados em consideração pelos governos, existe a advertência de que estejam sendo escamoteados $^{63}$. Engajamento, entusiasmo, habilidades, apoio e receptividade organizacional são preditores da advocacy entre os enfermeiras(os) ${ }^{64}$, além do interesse pessoal em questões políticas e participação em organizações de classe que justificariam a inclusão da temática nos currículos ${ }^{65}$.

Somada à percepção de pouca autoridade para modificar normas assistenciais e o interesse de enfermeira(o)s em advocacy, tal prática permanece incipiente ${ }^{66}$ no Brasil, mesmo que ainda concentrada em melhorias nos resultados individuais da saúde do usuário do sistema de saúde ${ }^{66}$. A crítica sobre as visões de políticas neoliberais associadas às disparidades de saúde no Brasil explicam o obstáculo ao envolvimento de enfermeira(o)s na luta política contra condições precárias de trabalho provocadas por medidas de redução de custos $^{67}$ que reduzem a qualidade da assistência. Como resultado da participação limitada na política governamental de saúde, a voz da(o) enfermeira(o) é silenciada ${ }^{66}$. Portanto, justifica-se educar enfermeira(o)s para seu protagonismo político. Assim, esta pesquisa considerou que qualquer processo educacional deve estimular um desejo de ação em direção à mudança social que aborda a desigualdade e a opressão $0^{68}$. A melhor maneira de ajudar os outros a identificar um problema, assim como a compreendê-lo, é por meio do desenvolvimento do julgamento crítico a partir do qual as soluções podem ser formuladas ${ }^{69}$.

A abordagem da violência obstétrica exige a sinergia de ações multidisciplinares nacionais e iniciativas internacionais ${ }^{70} \mathrm{e}$ o envolvimento da sociedade civil para atender às demandas para melhoria da qualidade dos cuidados com a saúde das mulheres e das crianças no nascimento ${ }^{71}$. Inegavelmente é um problema de saúde pública ${ }^{72}$ caracterizado pelos abusos físicos, sexuais e verbais somados ao estigma e à discriminação, à inobservância de padrões de práticas profissionais, às relações de baixa qualidade entre mulheres e profissionais e às condições limitadas dos sistemas de saúde ${ }^{73}$. Apesar disso, as puérperas declaram satisfação com a atuação de enfermeira(o)s em serviço de acolhimento ${ }^{74}$, apesar da violência interprofissional simbólica restringindo as atividades desses profissionais em centro obstétrico ${ }^{75}$. Por isso é essencial fortalecer, nos programas de graduação em Enfermagem, o papel da educação crítica, que promove o entendimento pelos estudantes sobre competências para a advocacy.

Propõem-se mudanças no modelo de assistência obstétrica cientificamente respaldadas por um modelo colaborativo, com a participação de enfermeira(o)s obstetras na assistência e na tomada de decisão clínica durante as fases do parto ${ }^{76}$ Enfermeira(o) s gestoras(es) são agentes de implantação da prática de Enfermagem baseada em evidências, oferecendo uma cultura $e$ um ambiente de suporte para elevar a qualidade da assistência pela tradução de evidências em sua inovação ${ }^{77}$.

É possível afirmar que esta pesquisa contribui para o conhecimento científico naárea de advocacy ao propor uma tradução de conhecimentos sob a forma de recomendações ao avanço da prática baseada em evidências ${ }^{12}$ tanto na educação quanto na prática, prioritariamente por enfermeira(o)s na transversalidade da assistência obstétrica humanizada. A importância final consiste em transformar a visão da população desenhando trilhas para ações e estratégias para que enfermeira(o)s possam advogar em defesa de direitos humanos e obstétricos das mulheres. Tais trilhas podem ainda inspirar a mesma renovação para a equipe multiprofissional. A análise e a interpretação das evidências coletadas nesta pesquisa resultaram na formulação de recomendações originais (ver Quadros 1-4) cuja contribuição constitui objeto para o delineamento de uma série de projetos de pesquisa de ensino, impacto social e avaliação de serviços. O foco é o contexto de implementação do PHPN, o conteúdo e a consulta às partes interessadas, que corroboram os resultados sobre a complexidade do processo de formulação de programas e políticas, em face de pressões conflitantes. ${ }^{78}$ Pela natureza de seus conteúdos, as recomendações servem de inspiração para uma reflexão a posteriori pelo(a)s leitore(a)s e as contribuições originais desta pesquisa podem servir para a implantação de múltiplas iniciativas relacionadas à prática da advocacy.

\section{CONCLUSÃO E IMPLICAÇÕES PARA A PRÁTICA}

Cumpre destacar três limitações metodológicas. A primeira refere-se aos dados compilados no relatório gerado pela plataforma Opinio, o qual não permitiu corresponder às respostas à variável sexo da(o) respondente, nem à sua identificação, ao prover as respostas qualitativas às perguntas abertas, inviabilizada, assim, a análise qualitativa das respostas providas pelas 56 mulheres que responderam o formulário destinado ao público geral. A segunda 


\section{Advocacy e violência obstétrica}

Zanchetta MS, Santos WS, Souza KV, Pina VR, Hwu H, Stahl H, Argumedo-Stenner H, Osei-Boateng J, Zimmerman R, Pena ÉD, Cabral IE, Carvalho ALO, Pereira AV, Vieira BDG, Alves VH, Felipe ICV, Guruge S, Amant OS, Costa E, Escobar HPV

Quadro 1. Recomendações de advocacy para(o) enfermeira(o). Objetivo 1- Capacitar enfermeira(o)s em advocacy para promoção de saúde das mulheres com destaque para proteção de seus direitos e para a implementação extensiva da PHPN. (Elaboradas pelos autores, 2020)

\begin{tabular}{|c|c|}
\hline Ação prioritária & Estratégias integradas de implantação \\
\hline $\begin{array}{l}\text { - Colaborar para o desenvolvimento e a disponibilização de recursos educativos } \\
\text { com a Associação Brasileira de Obstetrizes e Enfermeiros Obstetras (ABENFO), } \\
\text { a Associação Brasileira de Enfermagem, o Conselho Federal de Enfermagem } \\
\text { e os Conselhos Regionais de Enfermagem, por meio de programas (online e } \\
\text { presenciais) independentemente de suas áreas de prática profissional. }\end{array}$ & $\begin{array}{l}\text { - Desenvolver novos instrumentos, métodos e abordagens para o trabalho } \\
\text { educativo socialmente inclusivo relativo a direitos da mulher, respondendo } \\
\text { às particularidades e à diversidade da clientela feminina assistida na rede } \\
\text { de atenção primária, secundária e terciária de saúde no contínuo gravidez- } \\
\text { parto-pós-parto-nascimento-puerpério. }\end{array}$ \\
\hline $\begin{array}{l}\text { - Promover atividades de educação universitária, educação em serviço e } \\
\text { de desenvolvimento profissional para incrementar o nível de letramento } \\
\text { político da(o)s enfermeira(o)s. }\end{array}$ & $\begin{array}{l}\text { - Criar um sistema de mentoring/coaching na área de letramento político } \\
\text { para enfermeira(o)s e estudantes, a fim de ampliar redes de relações, } \\
\text { apoiar demandas específicas e estimular processos de atualização/ } \\
\text { educação permanente. }\end{array}$ \\
\hline $\begin{array}{l}\text { - Criar oportunidades práticas para estudantes para desenvolver habilidades } \\
\text { de advocacy nos macro-sistemas. }\end{array}$ & $\begin{array}{l}\text { - Aumentar a exposição da(o)s professores e estudantes a exemplos } \\
\text { práticos de advocacy realizados por enfermeira(o)s para redirecionamento } \\
\text { de ações políticas. }\end{array}$ \\
\hline $\begin{array}{l}\text { - Colaborar com profissionais da área jurídica para oferecer a(o)s } \\
\text { enfermeira(o)s capacitação específica sobre potenciais condutas antiéticas, } \\
\text { erros profissionais e danos não intencionais, além de implicações de } \\
\text { processos de judicialização do exercício profissional, com destaque para } \\
\text { enfermeira(o) s obstétrica(o)s. }\end{array}$ & $\begin{array}{l}\text { - Rever, em programas de graduação e pós-graduação em Enfermagem, o } \\
\text { possível redirecionamento do processo de produção acadêmico-científica } \\
\text { para abordar o impacto social e os resultados na qualidade dos cuidados } \\
\text { obstétricos, devido ao trabalho político de enfermeira(o)s engajada(o)s na } \\
\text { defesa dos direitos das mulheres e o PHPN. }\end{array}$ \\
\hline $\begin{array}{l}\text { - Liderar projetos de avaliação quanti-qualitativa dos impactos sociais da } \\
\text { capacitação e da práxis de advocacy dos direitos das mulheres por enfermeira(o) } \\
\text { s focalizando o respeito às diversidades, o cuidado centrado na pessoa, a } \\
\text { diminuição da desigualdade de gênero e o equilíbrio nas relações de poder. }\end{array}$ & $\begin{array}{l}\text { - Facilitar simulações para estudantes e enfermeira(o)s para } \\
\text { instrumentalizá-los para advocacy. }\end{array}$ \\
\hline \multirow[t]{2}{*}{$\begin{array}{l}\text { - Fortalecer programas de graduação em Enfermagem, o papel da educação } \\
\text { crítica que promove o entendimento pelos estudantes sobre competências } \\
\text { para a advocacy em Enfermagem. }\end{array}$} & $\begin{array}{l}\text { - Sistematizar com a administração das instituições de saúde novas } \\
\text { práticas administrativas padronizadas de responsabilização/engajamento } \\
\text { profissional para advocacy dos direitos das mulheres. }\end{array}$ \\
\hline & $\begin{array}{l}\text { - Estimular a realização de educação permanente em serviço para a equipe } \\
\text { administrativa sobre as recomendações do PHPN. }\end{array}$ \\
\hline
\end{tabular}

Quadro 2. Recomendações de advocacy para(o) enfermeira(o). Objetivo 2-Elevar o nível de conhecimento da sociedade civil sobre direitos das mulheres que utilizam serviços pré-natais e obstétricos para torná-la colaboradora na vigilância da implementação do PHPN. (Elaboradas pelos autores, 2020)

\begin{tabular}{|c|c|}
\hline Ação prioritária & Estratégias integradas de implantação \\
\hline $\begin{array}{l}\text { - Estabelecer articulações intersetoriais entre as Secretarias Municipais } \\
\text { e Estaduais de Saúde, Educação e Assistência Social e Direitos Humanos; } \\
\text { Ministério da Mulher, da Família e dos Direitos Humanos; Secretaria } \\
\text { do Trabalho, com lideranças religiosas e comunitárias, e associações de } \\
\text { moradores para a criação de estratégias para construção da capacidade } \\
\text { comunitária de liderança cidadã e participação popular no PHPN. }\end{array}$ & $\begin{array}{l}\text { - Estabelecer parceria entre a mídia profissional, setor empresarial e } \\
\text { ABENFO para ações integrativas para a produção e divulgação do material } \\
\text { informativo sobre direitos das mulheres. }\end{array}$ \\
\hline $\begin{array}{l}\text { - Conceber ações de promoção de saúde às trabalhadoras em colaboração } \\
\text { com a Associação Nacional de Enfermeiros do Trabalho. }\end{array}$ & $\begin{array}{l}\text { - Popularizar o conhecimento sobre a caracterização da violência obstétrica } \\
\text { e o reconhecimento de seus indicadores por meio da produção e divulgação } \\
\text { de material educativo, com linguagem acessível incluindo sinônimos } \\
\text { utilizados pelo senso comum. }\end{array}$ \\
\hline $\begin{array}{l}\text { - Decodificar para linguagem popular a linguagem jurídica presente no } \\
\text { PHPN, disseminando-a entre a população feminina, assim como entre os } \\
\text { profissionais das áreas de saúde, assistência social e educação. }\end{array}$ & $\begin{array}{l}\text { - Estabelecer parcerias com profissionais da atenção primária à saúde, em } \\
\text { especial, os Agentes Comunitários de Saúde, produzindo vídeos e videoclipes } \\
\text { educativos, visando a preencher lacunas de conhecimento sobre o PHNP } \\
\text { entre as mulheres e famílias cadastradas na Estratégia Saúde da Família. }\end{array}$ \\
\hline $\begin{array}{l}\text { - Colaborar com as autoridades da Polícia Civil e Polícia Militar para a } \\
\text { implementação de programas de sensibilização dos seus efetivos quanto à PHPN. }\end{array}$ & $\begin{array}{l}\text { - Criar serviço de atendimento de denúncia sobre violência obstétrica nos serviços } \\
\text { de saúde, que possa ir além da escuta oferecida pela ouvidoria institucional. }\end{array}$ \\
\hline $\begin{array}{l}\text { - Estabelecer parceria com o setor de entretenimento para a disseminação } \\
\text { das campanhas educativas para a sociedade civil. }\end{array}$ & $\begin{array}{l}\text { - Elaborar checklist sobre situações indicadoras de desrespeito pelos profissionais } \\
\text { aos direitos da mulher, extensivas à violência obstétrica, para ser compartilhado } \\
\text { na primeira consulta pré-natal, e discutido nas consultas subsequentes. }\end{array}$ \\
\hline $\begin{array}{l}\text { - Favorecer espaços seguros para denunciar a violência obstétrica e a } \\
\text { violência contra a mulher, de maneira geral. }\end{array}$ & le \\
\hline
\end{tabular}


Quadro 3. Recomendações de advocacy para(o) enfermeira(o). Objetivo 3 - Redesenhar alianças com grupos da sociedade civil na área de defesa dos direitos da mulher para ampliar vozes da população feminina e implantar ações extensivas de sensibilização de grupos de mulheres socialmente vulneráveis. (Elaboradas pelos autores, 2020)

\begin{tabular}{|c|c|}
\hline Ação prioritária & Estratégias integradas de implantação \\
\hline $\begin{array}{l}\text { - Promover educação para as mulheres no prisma de educação por pares, } \\
\text { sobre os seus papéis e suas contribuições enquanto usuárias informadas } \\
\text { sobre direitos femininos/obstétricos, numa perspectiva de participação } \\
\text { popular, cidadania, sentidos de grupalidade/ engajamento coletivo, } \\
\text { defensoria de grupos, entre outros. }\end{array}$ & $\begin{array}{l}\text { - Garantir o funcionamento dos grupos de gestantes nas unidades de } \\
\text { atendimento com periodicidade regular e participação de profissionais de } \\
\text { outras áreas relativas às múltiplas dimensões dos direitos das mulheres. }\end{array}$ \\
\hline $\begin{array}{l}\text { - Assessorar os grupos existentes para a criação de mecanismos de defesa } \\
\text { dos direitos das mulheres pautados no monitoramento local/estadual } \\
\text { da implementação do PHPN e sobre os casos denunciados de violência } \\
\text { obstétrica. }\end{array}$ & $\begin{array}{l}\text { - Colaborar com profissionais de informática e comunicação, assim como } \\
\text { com o empresariado de telecomunicação, para o desenvolvimento de } \\
\text { aplicativos para smartphones e vídeos para pessoas sem acesso à internet, } \\
\text { mas que tenham dispositivos eletrônicos. }\end{array}$ \\
\hline \multirow[t]{2}{*}{$\begin{array}{l}\text { - Promover o amplo debate sobre direitos obstétricos, negligência no } \\
\text { cuidado obstétrico ou violações do PHPN. }\end{array}$} & $\begin{array}{l}\text { - Divulgar mecanismos e protocolos para denúncia de casos de violência } \\
\text { obstétrica. }\end{array}$ \\
\hline & $\begin{array}{l}\text { - Provocar discussões institucionais sobre o efeito na sua reputação, } \\
\text { devido aos casos de violência contra a gestante e obstétrica tornados de } \\
\text { conhecimento público. }\end{array}$ \\
\hline
\end{tabular}

Quadro 4. Recomendações de advocacy para(o) enfermeira(o). Objetivo 4 - Mobilizar o capital humano e cultural das comunidades/ sociedade civil e seus grupos vulneráveis para reconstruir significados tradicionais quanto à naturalização/banalização da exposição à violência obstétrica. (Elaboradas pelos autores, 2020)

\begin{tabular}{|ll|}
\hline \multicolumn{1}{|c|}{ Ação prioritária } & \multicolumn{1}{c|}{ Estratégias integradas de implantação } \\
\hline $\begin{array}{l}\text { - Propor projetos de extensão universitária multi/interdisciplinares } \\
\text { centrados na população feminina jovem e adulta, com enfoque no } \\
\text { desvelamento de suas realidades sociais e experiências do processo } \\
\text { gestacional e de parto. }\end{array}$ & $\begin{array}{l}\text { - Assessorar professores e estudantes do sistema de ensino secundário e } \\
\text { universitário para a criação de comissão de saúde estudantil com foco na } \\
\text { educação por pares sobre direitos das mulheres. }\end{array}$ \\
$\begin{array}{l}\text { - Implantar fóruns comunitários contínuos, independentes e em sincronia } \\
\text { com os Conselhos Municipais de Saúde sobre advocacy dos direitos das } \\
\text { mulheres. }\end{array}$ & $\begin{array}{l}\text { - Criar agenda de trabalho com grupos representativos da academia, da } \\
\text { sociedade civil e grupos vulneráveis visando a definir propostas a serem } \\
\text { apresentadas nas conferências municipais, estaduais e nacional de saúde. }\end{array}$ \\
$\begin{array}{l}\text { - Colaborar com pesquisadores das áreas de ciências políticas, sociais e da } \\
\text { saúde para realizar pesquisas de avaliação e produzir críticas baseadas no } \\
\text { conhecimento e no monitoramento da implementação do PHPN. }\end{array}$ & $\begin{array}{l}\text { - Traduzir conhecimento científico produzido pela pesquisa local em } \\
\text { material educativo, ressignificando a cultura popular da banalização da } \\
\text { violência obstétrica, para instrumentalizar o letramento político coletivo nas } \\
\text { diferentes esferas da sociedade. }\end{array}$ \\
\hline
\end{tabular}

trata da impossibilidade de ter-se alcançado uma representatividade da diversidade de mulheres em suas vivências em serviços de saúde menos responsivos às questões de gênero. A terceira refere-se à não identificação dos respondentes online, que inviabilizou a participação de peritos naturais ${ }^{79}$ para a verificação da interpretação dos achados qualitativos. Assim, a tendência dos achados qualitativos pode ser parcialmente transferida para outros contextos sociais, já que pode não ser aplicável à diversidade social da clientela feminina brasileira. Entretanto, a pesquisa rigorosamente atendeu aos critérios de cientificidade ao observar questões de cultura, gênero, linguagem, advocacy, padrões de respeitabilidade, além do incitamento à retórica ${ }^{80}$.
Pretendeu-se ouvir as vozes das mulheres e do público geral sobre melhorias na qualidade da assistência obstétrica. As evidências sustentam a proposição de recomendações para a advocacy por enfermeira(o)s e o redesenho de práticas institucionais. A operacionalização das recomendações pode encorajar o desenvolvimento de pensamento político que seja convergente com as demandas da sociedade de obter condições para exercício sustentado da tomada de decisão devido ao letramento político coletivo. Pela conscientização quanto à imprescindibilidade da prevenção da violência obstétrica em vários espaços sociais, asseguraríamos o debate sobre o incremento de humanização extensiva e da governança compartilhada. $O$ conjunto de recomendações multidimensionais 
para advocacy, seus objetivos, ações prioritárias e estratégias integradas coadunam com a perspectiva global da promoção de saúde das mulheres. Assim, fortaleceríamos nossa capacidade de liderança social transformadora para atribuírem-se respostas aos anseios da sociedade civil.

\section{AGRADECIMENTOS}

Agradecemos à Francisco Vilela, Andreia de Carvalho e membros da Diretoria e associados do Sindicato dos Agentes Comunitários de Saúde do Rio de Janeiro (SINACS-RJ) pela inestimável ajuda na fase de recrutamento para a pesquisa, bem como os graduandos e pós-graduandos da Escola de Enfermagem da Universidade Federal de Minas Gerais, da Escola de Enfermagem Anna Nery (UFRJ), e da Escola de Enfermagem Aurora de Afonso Costa (UFF) que colaboraram no recrutamento e na coleta de dados apoiando os supervisores de pesquisa locais, assim como, as graduandas da Ryerson University. Nosso especial obrigada aos participantes da pesquisa que atenderam ao nosso convite e compartilharam suas experiências e opiniões. Agradecemos ainda à Dra. Denize Bouttelet Munari e à Dra. Ana Beatriz A. Queiroz pela revisão crítica da versão preliminar do manuscrito. À Sandra Moreira Val, revisora autônoma, pela verificação gramatical de Português.

\section{FINANCIAMENTO}

Mitacs Globalink Research Award 2018 recebido pelas graduandas de Enfermagem, Hannah Stahl (\#IT 12476) e Hilary Hwu (\# IT 12473) e pela graduanda de Serviço Social, Hannah Argumedo-Stenner (\#IT 12401), da Ryerson University. Toronto, Canadá.

Ryerson University President Office and Faculty of Community Services, Seed Grant 2019.

\section{CONTRIBUIÇÕES DOS AUTORES}

Desenho do estudo. Margareth Santos Zanchetta. Walterlânia Silva Santos. Kleyde Ventura de Souza. Hilary Hwu. Hannah Stahl. Hannah Argumedo-Stenner. Érica Dumont Pena. Ivone Evangelista Cabral. Ana Luiza de Oliveira Carvalho. Audrey Vidal Pereira. Bianca Dargam Gomes Vieira. Valdecyr Herdy Alves. Ingryd Cunha Ventura Felipe. Sepali Guruge. Oona St.-Amant. Edwaldo Costa. Haydée Padilla Vda de Escobar.

Aquisição de dados. Margareth Santos Zanchetta. Walterlânia Silva Santos. Kleyde Ventura de Souza. Hilary Hwu. Hannah Stahl. Hannah Argumedo-Stenner. Érica Dumont Pena. Ivone Evangelista Cabral. Ana Luiza de Oliveira Carvalho. Audrey Vidal Pereira. Bianca Dargam Gomes Vieira. Valdecyr Herdy Alves. Ingryd Cunha Ventura Felipe. Sepali Guruge. Oona St.-Amant. Edwaldo Costa. Haydée Padilla Vda de Escobar.

Análise de dados e interpretação dos resultados. Margareth Santos Zanchetta. Walterlânia Silva Santos. Kleyde Ventura de Souza. Vanessa Rodrigues Pina. Hilary Hwu. Hannah Stahl. Hannah Argumedo-Stenner. Juliet Osei-Boateng. Rebecca
Zimmerman. Érica Dumont Pena. Ivone Evangelista Cabral. Ana Luiza de Oliveira Carvalho. Audrey Vidal Pereira. Bianca Dargam Gomes Vieira. Valdecyr Herdy Alves. Ingryd Cunha Ventura Felipe. Sepali Guruge. Oona St.-Amant. Edwaldo Costa. Haydée Padilla Vda de Escobar.

Redação e revisão crítica do manuscrito. Margareth Santos Zanchetta. Walterlânia Silva Santos. Kleyde Ventura de Souza. Vanessa Rodrigues Pina. Hilary Hwu. Hannah Stahl. Hannah Argumedo-Stenner. Juliet Osei-Boateng. Rebecca Zimmerman. Érica Dumont Pena. Ivone Evangelista Cabral. Ana Luiza de Oliveira Carvalho. Audrey Vidal Pereira. Bianca Dargam Gomes Vieira. Valdecyr Herdy Alves. Ingryd Cunha Ventura Felipe. Sepali Guruge. Oona St.-Amant. Edwaldo Costa. Haydée Padilla Vda de Escobar.

Aprovação da versão final do artigo. Margareth Santos Zanchetta. Walterlânia Silva Santos. Kleyde Ventura de Souza. Vanessa Rodrigues Pina. Hilary Hwu. Hannah Stahl. Hannah Argumedo-Stenner. Juliet Osei-Boateng. Rebecca Zimmerman. Érica Dumont Pena. Ivone Evangelista Cabral. Ana Luiza de Oliveira Carvalho. Audrey Vidal Pereira. Bianca Dargam Gomes Vieira. Valdecyr Herdy Alves. Ingryd Cunha Ventura Felipe. Sepali Guruge. Oona St.-Amant. Edwaldo Costa. Haydée Padilla Vda de Escobar.

Responsabilidade por todos os aspectos do conteúdo e a integridade do artigo publicado. Margareth Santos Zanchetta. Walterlânia Silva Santos. Kleyde Ventura de Souza. Vanessa Rodrigues Pina. Hilary Hwu. Hannah Stahl. Hannah ArgumedoStenner. Juliet Osei-Boateng. Rebecca Zimmerman. Érica Dumont Pena. Ivone Evangelista Cabral. Ana Luiza de Oliveira Carvalho. Audrey Vidal Pereira. Bianca Dargam Gomes Vieira. Valdecyr Herdy Alves. Ingryd Cunha Ventura Felipe. Sepali Guruge. Oona St.-Amant. Edwaldo Costa. Haydée Padilla Vda de Escobar.

\section{EDITOR ASSOCIADO}

\author{
Stela Maris de Mello Padoin (D)
}

\section{EDITOR CIENTÍFICO}

\author{
Marcelle Miranda da Silva (iD
}

\section{REFERÊNCIAS}

1. Clark CS. A call to conscience and action: on the nurse manifest project and creating change [Internet]. The Nursing Manifesto; 2013 [citado 2020 abr 23]. Disponível em: https://nursemanifest.com/2013/06/07/ on-the-nurse-manifest-project-and-creating-change/

2. Nursing Now Brasil. Carta de Brasilia - valorizacao da Enfermagem [Internet]. Brasília: Nursing Now Brasil; 2019 [citado 2020 abr 24]. Disponível em: http://nursingnowbrasil.com.br/arquivos/carta_de_brasilia. pdf

3. Spenceley SM, Reutter L, Allen MN. The road less traveled: nursing advocacy at the policy level. Policy Polit Nurs Pract. 2006;7(3):180-94 http://dx.doi.org/10.1177/1527154406293683. PMid:17071705.

4. MacDonnell JA. Fostering nurses' political knowledges and practices: education and political activation in relation to lesbian health ANS Adv Nurs Sci. 2009;32(2):158-72. http://dx.doi.org/10.1097/ ANS.0b013e3181a3ddd9. PMid:19461232. 
5. Cordova PB, Steck MBW, Vermeesch A, Pierre N, Rankin A, Ohlendorf JM et al. Health policy engagement among graduate nursing students in the United States. Nurs Forum. 2019;54(1):38-44. http://dx.doi. org/10.1111/nuf.12295. PMid:30196564.

6. MacDonnell JA, Buck-MacFadyen E. How activism features in the career lives of four generations of Canadian nurses. Policy Polit Nurs Pract. 2017 jan;17(2):218-230. PMid:28558602.

7. Buck-McFadyen E, MacDonnell J. Contested practice: political activism in nursing and implications for nursing education. Int $\mathrm{J}$ Nurs Educ Scholarsh. 2017 jul;14(1):20160026. http://dx.doi.org/10.1515/ ijnes-2016-0026. PMid:28749781.

8. Decreto $\mathrm{n}^{\circ} 7.345$, de 27 de outubro de 2010 (BR). Acordo Quadro entre o Governo da República Federativa do Brasil e o Governo do Canadá para Cooperação em Ciência, Tecnologia e Inovação instituído pelo Decreto ํㅜ 7.345, de 27 de outubro de 2010 firmado em São Paulo, em 17 de novembro de 2008 Diário Oficial da União [periódico na internet] São Paulo, 27 out 2010 [citado 2018 nov 14]. Disponível em: http://www. planalto.gov.br/ccivil_03/_ato2007-2010/2010/decreto/D7345.htm

9. Government of Canada. Canada's Feminist International Assistance Policy [Internet]. Ottawa: Government of Canada; 2020 [citado 2020 abr 24]. Disponível em: https://www.international.gc.ca/world-monde/ issues_development-enjeux_developpement/priorities-priorites/policypolitique.aspx?lang=eng

10. Zanchetta MS, Santos WS, Felipe ICV, Correia DMS. Reflections on the basis for the expansion of nursing partnerships between Brazil-Canada. Rev Eletr Enferm. 2019;21(57000):1-6.

11. Portaria $n^{\circ} \mathbf{5 6 9}$, de $1^{\circ}$ de Junho de 2000 (BR, Ministério da Saúde). Programa de Humanização no Pré-natal e Nascimento. Ministério da Saúde [periódico na internet], Brasília, jun 2000 [citado 2020 abr 24]. Disponível em: http://bvsms.saude.gov.br/bvs/saudelegis/gm/2000/ prt0569_01_06_2000_rep.html

12. Graham ID, Logan J, Harrison MB, Straus SE, Tetroe J, Caswell W et al. Lost in knowledge translation: time for a map? J Contin Educ Health Prof. 2006 dez;26(1):13-24. http://dx.doi.org/10.1002/chp.47. PMid:16557505.

13. Hill N. Understanding obstetric violence as violence against mothers through the lens of matricentric feminism. MIRCI [Internet]. 2019; [citado 2020 abr 24];10(1-2):233-43. Disponível em: https://jarm.journals.yorku. ca/index.php/jarm/article/view/40566/36737

14. Catallo C. Should nurses be knowledge brokers? Competencies and organizational resources to support the role. Can J Nurs Leadersh. 2015;28(1):24-37. http://dx.doi.org/10.12927/cjnl.2015.24235. PMid:26154118.

15. Savage V, Castro A. Measuring mistreatment of women during childbirth: a review of terminology and methodological approaches. Reprod Health. 2017 out $26 ; 14(1): 138$. http://dx.doi.org/10.1186/s12978-017-0403-5. PMid:29073914.

16. World Health Organization. Prevention and elimination of disrespect and abuse during childbirth [Internet]. Geneva:WHO;2014 [citado 2020 abr 24]. Disponível em: https://www.who.int/reproductivehealth/topics/ maternal_perinatal/statement-childbirth/en/

17. Bohren MA, Mehrtash H, Fawole B, Maung TM, Balde MD, Maya E et al. How women are treated during facility-based childbirth in four countries: a cross-sectional study with labour observations and communitybased surveys. Lancet. 2019 nov;394(10210):1750-63. http://dx.doi. org/10.1016/S0140-6736(19)31992-0. PMid:31604660.

18. Torloni MR, Betrán AP, Belizán JM. Born in Brazil: shining a light for change. Reprod Health. 2016 out;13(1):133. http://dx.doi.org/10.1186/ s12978-016-0247-4. PMid:27756402

19. Lansky S, Souza KV, Peixoto ERM, Oliveira BJ, Diniz CSG, Vieira NF et al. Obstetric violence: influences of the senses of birth exhibition in pregnant women childbirth experience. Cien Saude Colet. 2019;24(8):2811-24. http://dx.doi.org/10.1590/1413-81232018248.30102017. PMid:31389530.

20. Williams CR, Meier BM. Ending the abuse: the human rights implications of obstetric violence and the promise of rights-based policy to realise respectful maternity care. Sex Reprod Health Matters. 2019 jan;27(1):1691899. http://dx.doi.org/10.1080/26410397.2019.16918 99. PMid:31809245.
21. Heckert C. The bureaucratic violence of the health care system for pregnant immigrants on the United States-Mexico border. Hum Organ. 2020;79(1):33-42. http://dx.doi.org/10.17730/0018-7259.79.1.33

22. Nunes MCM, Gouveia LMR, Reis-Queiroz J, Hoga AKL. Birth care providers experiences and practices in a Brazilian alongside midwifery unit: an ethnographic study. Glob Qual Nurs Res. 2016;3:2333393616670212. http://dx.doi.org/10.1177/2333393616670212. PMid:28508020.

23. Diniz CSG, Rattner R, d'Oliveira AFPL, Aguiar JM, Niy DM. Disrespect and abuse in childbirth in Brazil: social activism, public policies and providers' training. Reprod Health Matters. 2018;26(53):19-35. http:// dx.doi.org/10.1080/09688080.2018.1502019. PMid:30106349.

24. Biscegli TS, Grio JM, Melles LC, Ribeiro SRMI, Gonsaga AT. Obstetrical violence: profile assistance of a state of São Paulo interior maternity school. CuidArte Enferm [Internet]. 2015; [citado 2020 abr 24];9(1):18 25. Disponível em: https://pesquisa.bvsalud.org/portal/resource/pt/ bde-26951

25. Carvalho IS, Brito RS. Forms of obstetric violence experienced by mothers who had normal birth. Enferm Glob [Internet]. 2017; [citado 2020 abr 24];16(3):89-97. Disponível em: https://revistas.um.es/eglobal/ article/view/250481

26. Leal MC, Szwarcwald CL, Almeida PVB, Aquino EML, Barreto ML, Barros $F$ et al. Reproductive, maternal, neonatal and child health in the 30 years since the creation of the Unified Health System (SUS). Cien Saude Colet. 2018 jun;23(6):1915-28. http://dx.doi.org/10.1590/141381232018236.03942018. PMid:29972499.

27. Laako H. Understanding contested women's rights in development: the Latin American campaign for the humanisation of birth and the challenge of midwifery in Mexico. Third World Q. $2017 \mathrm{fev;38(2):379-96.}$ http://dx.doi.org/10.1080/01436597.2016.1145046.

28. Davis DA. Obstetric racism: the racial politics of pregnancy, labor, and birthing. Med Anthropol. 2019 out;38(7):560-73. http://dx.doi.org/10.1 080/01459740.2018.1549389. PMid:30521376.

29. Leal MC, Gama SGN, Pereira APE, Pacheco VE, Carmo CN, Santos RV The color of pain: racial iniquities in prenatal care and childbirth in Brazil. Cad Saude Publica. 2017;33(33, Suppl 1):e00078816. PMid:28746555.

30. Batista LE, Rattner D, Kalckmann S, Oliveira MCG. Humanization in healthcare and racial inequalities: an intervention proposal. Saude Soc. 2016;25(3):689-702. http://dx.doi.org/10.1590/s0104-12902016146290.

31. Theophilo RL, Rattner D, Pereira EL. The vulnerability of Afro-Brazilian women in perinatal care in the Unified Health System: analysis of the Active Ombudsman survey. Cien Saude Colet. 2018;23(11):3505-16 http://dx.doi.org/10.1590/1413-812320182311.31552016. PMid:30427424.

32. Pinto LSS, Oliveira IMP, Pinto ESS, Leite CBC, Melo AN, Deus MCBR Women's protection public policies: evaluation of health care for victims of sexual violence. Cien Saude Colet. 2017;22(5):1501-8. http://dx.doi. org/10.1590/1413-81232017225.33272016. PMid:28538921.

33. Nazareth JV, Souza KV, Beinner MA, Barra JS, Brüggemann OM, Pimenta AM. Special attention to women experiencing high-risk pregnancy: delivery, care assistance and neonatal outcomes in two Brazilian maternity wards. Midwifery. 2017 out;53:42-8. http://dx.doi. org/10.1016/j.midw.2017.07.009. PMid:28750275.

34. Teixeirense MMS, Santos SLS. From expectation to experience: humanizing childbirth in the Brazilian National Health System. Interface. 2018 abr;22(65):399-410. http://dx.doi.org/10.1590/1807-57622016.0926.

35. Leal MC, Bittencourt SA, Esteves-Pereira AP, Ayres BVS, Silva LBRAA Thomaz EBAF et al. Progress in childbirth care in Brazil: preliminary results of two evaluation studies. Cad Saude Publica. 2019;35(7):e00223018. PMid:31340337.

36. Vasconcelos MFF, Nicolotti CA, Silva JF, Pereira SMLR. In-between policies (CEH--Continuing Education in Health and NHP--Humanization National Policy): towards a way to educate in/for the Brazilian Nationa Health System. Interface. 2016;20(59):981-91.

37. Portaria $\mathrm{n}^{\circ} \mathbf{1 . 1 3 0}$, de 5 de Agosto de 2015 (BR, Ministério da Saúde) Política Nacional de Atenção Integral à Saúde da Criança. Ministério da Saúde [periódico na internet], Brasília, 2015 [citado 2020 abr 24] Disponível em: http://bvsms.saude.gov.br/bvs/saudelegis/gm/2015/ prt1130_05_08_2015.html

38. Ministério da Saúde (BR). Linha de cuidado para a atenção integral à saúde de crianças, adolescentes e suas famílias em situação de 


\section{Advocacy e violência obstétrica}

Zanchetta MS, Santos WS, Souza KV, Pina VR, Hwu H, Stahl H, Argumedo-Stenner H, Osei-Boateng J, Zimmerman R, Pena ÉD, Cabral IE, Carvalho ALO, Pereira AV, Vieira BDG, Alves VH, Felipe ICV, Guruge S, Amant OS, Costa E, Escobar HPV

violências: orientação para gestores e profissionais de saúde [Internet] Brasília: Ministério da Saúde; 2010 [citado 2020 abr 24]. Disponível em: https://bvsms.saude.gov.br/bvs/publicacoes/linha_cuidado_criancas_ familias_violencias.pdf

39. Moreira MADM, Lustosa AM, Dutra F, Barros EO, Batista JVB, Duarte MCS. Public humanization policies: integrative literature review. Cien Saude Colet. 2015;20(10):3231-42. http://dx.doi.org/10.1590/1413812320152010.10462014. PMid:26465863.

40. Thomas J. Doing critical ethnography. Newbury Park: Sage; 1993. http:// dx.doi.org/10.4135/9781412983945.

41. Ellenbecker CH, Fawcett J, Jones EJ, Mahoney D, Rowlands B, Waddell A. A staged approach to educating nurses in health policy. Policy Polit Nurs Pract. 2017 fev;18(1):44-56. http://dx.doi.org/10.1177/1527154417709254. PMid:28558520.

42. Staebler S, Campbell J, Cornelius P, Fallin-Bennett A, Fry-Bowers E, Kung YM et al. Policy and political advocacy: comparison study of nursing faculty to determine current practices, perceptions, and barriers to teaching health policy. J Prof Nurs. 2017 set;33(5):350-5. http://dx.doi. org/10.1016/j.profnurs.2017.04.001. PMid:28931482.

43. Sue VM, Ritter LA. Conducting online surveys. Thousand Oaks: Sage Publications. Sampling; 2012. p. 33-50. http://dx.doi. org/10.4135/9781506335186

44. Grove SK, Burns N, Gray JR. The practice of nursing research: appraisal, synthesis and generation of evidence. 7th ed. St. Louis: Elsevier Saunders 2013. $752 \mathrm{p}$.

45. Paillé $P$, Mucchielli A. L'analyse qualitative en sciences humaines et sociales [francês]. Paris: Armand Colin; 2016. 432 p.

46. Faleiros F, Käppler C, Pontes FAR, Silva SSC, Goes FSN, Cucick CD. Use of virtual questionnaire and dissemination as a data collection strategy in scientific studies. Texto Contexto Enferm. 2016 out;25(4):1-6. http://dx.doi.org/10.1590/0104-07072016003880014.

47. Paiva CCN, Caetano R. Evaluation of the implementation of sexual and reproductive health actions in primary care: scope review. Esc Anna Nery. 2020;24(1):e20190142. http://dx.doi.org/10.1590/2177-9465ean-2019-0142.

48. Guruge S, Zanchetta MS, Roche B, Lucchese SP. New lives, new challenges: access and utilization of IPV-related health, social, and settlement services among Portuguese-speaking immigrant women. Rev Eletr Enf. 2019 dez;210(55653):1-9

49. Hyman I, Vahabi M, Bailey A, Patel S, Guruge S, Wilson-Mitchell Ket al Taking action on violence through research, policy, and practice. Glob Health Res Policy. 2016;1:6. http://dx.doi.org/10.1186/s41256-0160006-7. PMid:29202056.

50. Tajuddin MA, Alputila MJ, llyas A. Justice for women in handling the case of household violence through integrated criminal justice system (study in Merauke District). Enferm Clin. 2020;30(Suppl 2):394-7. http:// dx.doi.org/10.1016/j.enfcli.2019.11.006. PMid:32204195.

51. Ferreira MC, Monteschio LVC, Teston EF, Oliveira L, Serafim D, Marcon SS. Perceptions of nursing professionals about humanization of childbirth in a hospital environment. Rev Rene. 2019;20:1-9.

52. Ali HM, Boddy J, Ewart J. Exploring the use of public relations in organising activism: implications for addressing gender-based violence in the developing world. Asia Pac Public Relat J. 2016;17(2):46-61.

53. South J, Connolly AM, Stansfield JA, Johnstone P, Henderson G, Fenton KA. Putting the public (back) into public health: leadership, evidence and action. J Public Health. 2019;41(1):10-7. http://dx.doi.org/10.1093/ pubmed/fdy041. PMid:29546426.

54. World Health Organization. Track 1: Community empowerment [Internet] Geneva:WHO; 2010 [citado 2020 abr 24]. Disponível em: https://www. who.int/healthpromotion/conferences/7gchp/track1/en/

55. World Health Organization. Women's and children's health: evidence of impact of human rights [Internet]. Geneva:WHO; 2013 [citado 2020 abr 24]. Disponível em: https://www.who.int/maternal_child_adolescent/ documents/women_children_human_rights/en/

56. Lokugamage AU, Pathberiya SDC. Human rights in childbirth, narratives and restorative justice: a review. Reprod Health. 2017;14(1):17. http:// dx.doi.org/10.1186/s12978-016-0264-3. PMid:28148304
57. Ghrayeb IK, Silbermann M. Empowering women nurses can make a difference. Palliat Med Hosp Care Open J. 2018 ago;4(1):e1-2. http:// dx.doi.org/10.17140/PMHCOJ-4-e006.

58. Brownie S, Wahedna AH, Crisp N. Nursing as a pathway to women's empowerment and intergenerational mobility. J Clin Nurs. 2018;27(2122):4050-7. http://dx.doi.org/10.1111/jocn.14540. PMid:29791745

59. Gomes SC, Teodoro LPP, Pinto AGA, Oliveira DR, Quirino GS, Pinheiro AKB. Rebirth of childbirth: reflections on medicalization of the Brazilian obstetric care. Rev Bras Enferm. 2018 out;71(5):2594-8. http://dx.doi. org/10.1590/0034-7167-2017-0564. PMid:30304195.

60. Shabot SC, Korem K. Domesticating bodies: the role of shame in obstetric violence. Hypatia. 2018 ago;33(3):384-401. http://dx.doi.org/10.1111/ hypa.12428.

61. Marrero L, Brüggemann OM. Institutional violence during the parturition process in Brazil: integrative review. Rev Bras Enferm. 2018 maio;71(3):1152-61. http://dx.doi.org/10.1590/0034-7167-2017-0238. PMid:29924146.

62. Cesario SK, Moran B. Empowering the girl child, improving global health J Obstet Gynecol Neonatal Nurs. 2017 maio;46(3):e65-74. http://dx.doi. org/10.1016/j.jogn.2016.08.014. PMid:28285003.

63. Cuff PA, Patel DM, Perez MM. Empowering women and strengthening health systems and services through investing in nursing and midwifery enterprise. Lessons from lower-income countries: workshop summary Washington: National Academies Press; 2015. 119 p. http://dx.doi. org/10.17226/19005

64. World Health Organization. Transformando nosso mundo: a agenda 2030 para o desenvolvimento sustentável [Internet]. Geneva: WHO 2019 [citado 2020 abr 24]. Disponível em: https://nacoesunidas.org/ pos2015/agenda2030/

65. Yamin AE. Power, politics and knowledge claims: sexual and reproductive health and rights in the SDG era. Glob Policy. 2019;10(Suppl 1):52-60. http://dx.doi.org/10.1111/1758-5899.12598.

66. Jansson BS, Nyamathi A, Heidemann G, Bird M, Ward CR, BrownSaltzman $\mathrm{K}$ et al. Predicting levels of policy advocacy engagement among acute-care health professionals. Policy Polit Nurs Pract. 2016 fev;17(1):43-55. http://dx.doi.org/10.1177/1527154416644836. PMid:27151835.

67. Woodward B, Smart D, Benavides-Vaello S. Modifiable factors that support political participation by nurses. J Prof Nurs. 2016 jan;32(1):5461. http://dx.doi.org/10.1016/j.profnurs.2015.06.005. PMid:26802592.

68. Freire P. Education for critical consciousness. New York: Continuum 1973. 164 p.

69. Freire P. Educação como prática da liberdade. 23 ed. Rio de Janeiro: Paz e Terra; 1999. 149 p.

70. Lewinski AA, Simmons LA. Nurse knowledge and engagement in health policy making: findings from a pilot study. J Contin Educ Nurs. 2018:49(9):407-15. http://dx.doi.org/10.3928/00220124-20180813-06. PMid:30148538.

71. Sadler M, Santos MJDS, Ruiz-Berdún D, Rojas GL, Skoko E, Gillen P et al Moving beyond disrespect and abuse: addressing the structural dimensions of obstetric violence. Reprod Health Matters. 2016 maio;24(47):47-55. http://dx.doi.org/10.1016/j.rhm.2016.04.002. PMid:27578338.

72. Dias M, Machado VE. Obstetric violence in Brazil: an integrated multiple case study. Int J Humanit Soc Sci Rev. 2018;8(2):117-28.

73. Jardim DMB, Modena CM. Obstetric violence in the daily routine of care and its characteristics. Rev Lat Am Enfermagem. 2018;26:e3069http:// dx.doi.org/10.1590/1518-8345.2450.3069. PMid:30517571.

74. Araújo JL, Freitas RJM, Guedes MVC, Freitas MC, Monteiro ARM, Silva LMS. Brazilian Unified Health System and democracy: nursing in the context of crisis. Rev Bras Enferm. 2018;71(4):2066-71. http://dx.doi. org/10.1590/0034-7167-2017-0352. PMid:30156698.

75. Lopes GC, Gonçalves AC, Gouveia HG, Armellini CJ. Attention to childbirth and delivery in a university hospital: comparison of practices developed after network stork. Rev Lat Am Enfermagem. 2019 abr;27:e3139. PMid:31038633.

76. Moreira N, Souza N, Progianti J. Work conditions in the hospital: perceptions of obstetric nurses. Revista Enfermagem UERJ. 2017;25:e26999. http:// dx.doi.org/10.12957/reuerj.2017.26999. 
77. Bianchi M, Bagnasco A, Bressan V, Barisone M, Timmins F, Rossi S et al. A review of the role of nurse leadership in promoting and sustaining evidence-based practice. J Nurs Manag. 2018 nov;26(8):918-32. http:// dx.doi.org/10.1111/jonm.12638. PMid:30198088.

78. Kennedy C, O'Reilly P, O'Connell R, O'Leary D, Fealy G, Hegarty JM et al. Integrative review; identifying the evidence base for policymaking and analysis in health care. J Adv Nurs. 2019 dez;75(12):3231-45. http:// dx.doi.org/10.1111/jan.14121. PMid:31222800.
79. Sandelowski M. The call to experts in qualitative research. Res Nurs Health. 1998 out;21(5):467-71. http://dx.doi.org/10.1002/ (SICI)1098-240X(199810)21:5<467::AID-NUR9>3.0.CO;2-L. PMid:9761143.

80. Creswell JW, Poth CN. Qualitative inquiry and research design: choosing among five approaches. 4th ed. Thousand Oaks: Sage Publications; 2017. $488 p$.

a* O termo advocacy será utilizado com semântica da língua inglesa, ou seja, o de lutar por, exigir algo, pressionar por, argumentar sobre. Justificando-se seu uso devido à inexistência de uma palavra com significado plural correspondente na língua portuguesa.

b* O termo «direitos das mulheres» engloba direitos de acessar serviços desde o pré-natal até o puerpério (incluindo serviços materno-infantis) nos quais recebem os cuidados profissionais realizados durante o pré-natal, parto/nascimento e puerpério.

c* Na pesquisa original, o termo "público em geral" referiu-se a qualquer pessoa que pudesse responder o formulário online, já que a gravidez constitui-se um fenômeno social que abrange diferentes membros da sociedade, independentemente de sexo, gênero, idade, estado civil, situação familiar. Isso levou algumas mulheres a escolher responder a esse formulário e não o outro, exclusivo para mulheres. 